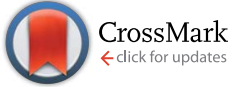

Cite this: RSC Adv., 2015, 5, 80098

\title{
The structural evolution of an isoindigo-based non- fullerene acceptor for use in organic photovoltaics $\uparrow$
}

\author{
Seth M. McAfee,,$_{+}^{\mathrm{a}}$ Jessica M. Topple, ${ }^{\mathrm{b}}$ Jon-Paul Sun, ${ }^{\mathrm{b}}$ Ian G. Hill ${ }^{* b}$ \\ and Gregory C. Welcht*a
}

The structural evolution of a functional isoindigo-based non-fullerene acceptor led to the development of three new materials to address the deficiencies of the original framework. Owing to the versatility of the structure and the flexibility of the synthetic procedures, these three new materials were accessible from previously optimized reaction conditions and similar precursor materials. The influence of structural modification on the optical, electrochemical and thermal properties were assessed and correlated with DFT calculations to provide compelling evidence for the effect of each substitution and how they relate to each particular adaptation. The structure-property relationships were investigated for their photovoltaic performance in solution processable $\mathrm{BHJ}$ devices fabricated in inverted architectures. Evaluation of device performance demonstrated that a single modification did not improve on the efficiency of the original structure, but the combination of both induced nonplanarity, and increased electron affinity of the fourth iteration showed the potential of our framework, with PCE reaching $1.9 \%$.

Received 18th August 2015

Accepted 14th September 2015

DOI: $10.1039 / c 5 r a 16696 a$

www.rsc.org/advances year this rapidly evolving field has seen significant improvements in the performance of non-fullerene based organic solar cells, and just in the last few months, PCEs are now exceeding $6 \%$, using small molecule acceptors. ${ }^{22-26}$

Key to the development of new high performance materials is to understand the structure-property relationships at play and identify the strengths and weaknesses of the framework. Considering this, successful non-fullerene small molecule acceptors are designed to exploit the properties that make fullerene derivatives such excellent electron acceptors while at the same time improving on their well-documented deficiencies including cost, synthetic accessibility and poor light harvesting properties. For more information on the history of fullerenes and how to replace them we refer the reader to several recent reviews. ${ }^{27-33}$

One of the most prominent classes of non-fullerene acceptors are based around perylene diimide (PDI) core structures, ${ }^{34-37}$ known for their large extinction coefficients and high electron mobilities. The structure-property relationships of perylene acceptors have been extensively studied, with the major obstacle facing PDI derivatives identified as their tendency for strong aggregation into crystalline domains. ${ }^{38,39}$ Therefore their designs are dictated by the requirement for bulky aliphatic side chains, ${ }^{\mathbf{4 0 , 4 1}}$ or framework substituents, ${ }^{\mathbf{4 2 - 4 4}}$ to mitigate large-scale aggregate formation. Despite the favorable accessibility of the perylene building block, their synthesis can be demanding and low yielding, with the formation of unwanted isomers a persistent challenge limiting their synthetic scalability. ${ }^{45}$

\footnotetext{
${ }^{a}$ Department of Chemistry, Dalhousie University, 6274 Coburg Road, Halifax, Nova Scotia, Canada B3H 4R2. E-mail: gregory.welch@ucalgary.ca

${ }^{b}$ Department of Physics, Dalhousie University, 6274 Coburg Road, Halifax, Nova Scotia, Canada $B 3 H 4 R 2$

$\dagger$ Electronic supplementary information (ESI) available: Includes complete experimental procedures, characterization data, DFT analysis, and device performance data. See DOI: 10.1039/c5ra16696a

\$ Present addresses: Department of Chemistry, University of Calgary, 2500 University Drive N.W., Calgary, Alberta, T2N 1N4.
} 
Small molecule non-fullerene acceptors that do not implement a PDI core structure have been demonstrated to offer key advantages in comparison to their PDI-based counterparts. These materials can be designed under similar principles as many PDI-based acceptors, ${ }^{46}$ but are not plagued by the same structural and synthetic limitations. They are usually simplistic in nature, and offer a modular structure accessible from a straightforward synthetic procedure..$^{4-49}$

The recent development of a high performance indacenodithiophene-based non-fullerene acceptor serves to highlight the importance of a versatile structure and the enormous potential for these materials to evolve and reach new echelons in performance. In this case, the incorporation of branched aliphatic side chains to the bridging thiophene units of original design,,$^{50}$ saw an approximately $60 \%$ increase in performance with device optimization. ${ }^{22}$ This was followed by a third iteration that instead fused the thiophene bridging units and returned the highest recorded performance non-fullerene acceptor to date at $6.8 \%$ PCE. ${ }^{25}$ Evidently, these small structural changes had a major influence on the performance of this class of materials, further demonstrating the influence of the structure on material properties and performance.

Considering the overwhelming potential for massive performance increases as a result of structural modification, we decided to take advantage of the versatility and synthetic accessibility of an isoindigo small molecule non-fullerene acceptor recently designed and synthesized in our lab. Oct$\mathbf{I I}(\text { ThPhth-1EP) })_{2}$ is a low-cost electron deficient small molecule that can be synthesized via a sustainable synthetic protocol from readily available building blocks. ${ }^{51}$ In terms of material properties, Oct-II(ThPhth-1EP) ${ }_{2}$ exhibited several desirable characteristics, (1) a broad and extended absorption profile efficient for light harvesting, (2) low-lying lowest unoccupied molecular orbital (LUMO) energy levels suitable for its use as an acceptor component in OPVs and (3) excellent thermal stability. OPV devices employing $\boldsymbol{p}$-DTS(FBTTh $\mathbf{2}_{2}$ as the donor component were found to have high open circuit voltages $\left(V_{\mathrm{OC}}\right)$ but suffered from poor current generation. While device engineering and innovative active layer processing can lead to significant performance increases, ${ }^{52-56}$ we instead decided to focus on synthetic chemistry to refine this initial framework in the pursuit of improved efficiencies.

Herein we detail the design, synthesis and characterization of three new isoindigo non-fullerene acceptors modeled from our initial structure and explore the influence of this structural evolution on material performance through proof-of-concept organic photovoltaic devices.

\section{Design and synthesis}

It is well known that the infinite tunability of organic small molecules enables systematic alterations to the molecular structure with the goal of realizing improved material performance. This advantageous feature has been exploited to improve the performance of our previously reported nonfullerene acceptor Oct-II(ThPhth-1EP) $)_{2}$, referred to hereafter as S1.

\subsection{Materials design}

Experimental evidence related to the poor device performance of $\mathbf{S 1}$ highlighted two main concerns, thin-film morphology and energy level alignment.

The most noticeable issue was the tendency of $\mathbf{S 1}$ to form crystalline domains ${ }^{, 51}$ as observed by thin-film X-ray diffraction (TF-XRD) and atomic force microscopy (AFM). Although as-cast films were amorphous, post-deposition thermal and solvent vapour annealing led to the materialization of crystalline domains. The best performance for devices with $\mathbf{S 1}$ as the acceptor component was achieved with the inclusion of a small volume fraction of 1,8-diiodooctane (DIO) in the active layer blend. The introduction of DIO induced a more subtle change to the blend morphology and so we propose that this improved efficiency results from a more favourable mixing of the active layer components.

Another area of interest was to increase the electronaccepting character of $\mathbf{S 1}$. This acceptor has a relatively high LUMO level of $-3.67 \mathrm{eV}$ relative to the vacuum, ${ }^{51}$ in comparison to many of the high performance small molecule non-fullerene acceptors in the literature, which tend to exist at approximately $-3.8 \mathrm{eV}$ or below. ${ }^{27}$ Therefore we had considered that perhaps a slight increase in the electron affinity of $\mathbf{S 1}$ could be beneficial for more efficient charge separation and lead to further increases in efficiency.

With theses considerations in mind, the structural evolution focused on two prominent design strategies often employed in the design on non-fullerene acceptors: (1) bulky substituents and induced non-planarity to reduce the tendency for strong $\pi$ $\pi$ interactions and large aggregate formation, and (2) strong electron-withdrawing functionalities to increase the $\pi$-accepting character of the molecular framework.

The systematic structural modification of $\mathbf{S 1}$ is depicted in Fig. 1, and has been devised to decouple the influence of introducing steric demand to- and increasing the electron affinity of- the $\pi$-conjugated system. The molecular design of $\mathbf{S 2}$ focused on introducing steric bulk to the $\pi$-conjugated backbone in the form of a naphthalimide terminal acceptor in place of the less encumbering phthalimide unit. Naphthalimide is another promising imide building block that has a notable use in some recent high performance non-fullerene acceptors..$^{57-59}$ Although, more importantly for our design, naphthalimide has been shown to reduce the overall crystallinity of a given material as a consequence of its steric demand. This has been communicated in previous work from our group with an analogous diketopyrrolopyrrole small molecule, ${ }^{60}$ which revealed the complete loss of a crystallization trace in the DSC thermogram upon the substitution of phthalimide for naphthalimide. It is expected that this feature will also manifest itself in $\mathbf{S} 2$ where steric bulk should judiciously disrupt the co-planarity of naphthalimide and the adjacent thiophene bridging unit and obstruct crystallization.

To address our interest in increasing the electron affinity of the $\pi$-conjugated backbone $\mathbf{S} \mathbf{3}$ was designed to incorporate a chlorine atom at the $5,5^{\prime}$ positions on the aromatic rings of the isoindigo core. The substitution of chlorine for hydrogen is 


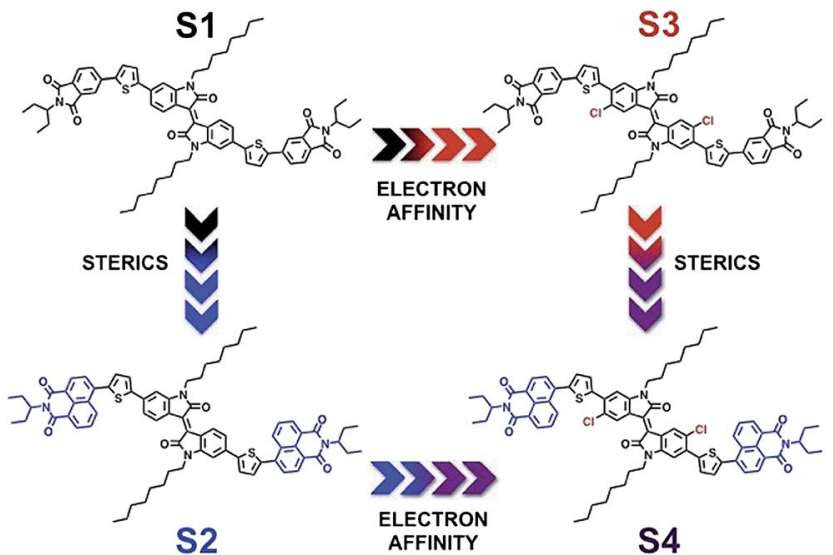

Fig. 1 The structural evolution of isoindigo non-fullerene acceptors with increased electron affinity and reduced crystallinity in pursuit of a favorable morphology and increased OPV device efficiencies.

proposed to serve a dual purpose, (1) increase the electron affinity by replacing hydrogen with the more electronegative chlorine atom, and (2) slightly disrupt the co-planarity between the isoindigo core and thiophene bridging unit as a result of the more sterically demanding chlorine atom.

The final structure, $\mathbf{S 4}$, represents an elegant design based on the concept that the sum is greater than the parts. The integration of a chlorinated isoindigo core within a naphthalimide terminated $\pi$-conjugated framework was desirable to synergistically tailor the energy levels of the material and cleverly distort backbone planarity in pursuit of a less crystalline and more favourable thin-film morphology that would translate into improved OPV device performance.

\subsection{Materials synthesis}

The following describes the synthetic strategies used to access isoindigo derivatives S2-4 (Scheme 1). We refer the reader to our previous work for the complete synthesis of $\mathbf{S 1}$, and the precursor materials relevant to the synthesis of $\mathbf{S 2 - 4 .}{ }^{{ }^{11}}$ The final isoindigo small molecules S1-4 were identified by ${ }^{1} \mathrm{H}$ and ${ }^{13} \mathrm{C}$ NMR spectroscopy, mass spectrometry and elemental analysis with ${ }^{1} \mathrm{H}^{1}{ }^{1} \mathrm{H}$ COSY NMR spectroscopy to confirm regio-selectivity of the direct heteroarylation couplings. Complete experimental details for all new precursors and final materials can be found in the Experimental section.

The isoindigo derivative $\mathbf{S} 2$ was synthesized from the same molecular core as $\mathbf{S 1}$, albeit with coupling to a naphthalimide, 1EP-Naph, rather than phthalimide, 1EP-Phth, terminal acceptor. This 1EP-Naph terminal acceptor was synthesized from its anhydride through a base catalyzed condensation with 1-ethylpropylamine $(0.98 \mathrm{~g}, 78 \%)$. The precursor molecular core, Oct-IITh $\mathbf{H}_{2}$, was then coupled with this terminal acceptor through Pd catalyzed direct heteroarylation employing the heterogeneous catalyst SiliaCat $\circledast$ DPP-Pd. The use of this heterogeneous catalyst for $\mathrm{C}-\mathrm{H}$ bond activation has proven to be a versatile synthetic strategy that has been extensively used within our research group. ${ }^{51,61-63}$ SiliaCat ${ }^{\circledR}$ DPP-Pd has been shown to not only match homogeneous alternatives, but also circumvent inert reaction conditions, and diminish trace Pd metal impurities in the final product. ${ }^{61}$ The use of the heterogeneous catalyst also simplified the reaction work up and purification since it can be easily removed from the soluble product simply through vacuum filtration. The filtrate was subsequently concentrated under reduced pressure and the product purified by flash column chromatography with $\mathrm{CH}_{2} \mathrm{Cl}_{2}$ as the eluent. The final product was isolated as a purple-black solid and washed with a hot solution of iPrOH to remove any residual polar impurities $(0.28 \mathrm{~g}, 63 \%)$.

The syntheses of isoindigo derivatives $\mathbf{S 3}$ and $\mathbf{S 4}$ was analogous to those of $\mathbf{S 1}$ and $\mathbf{S 2}$, the difference being the requirement of a chlorinated isoindigo precursor. The incorporation of halogen atoms to a final isoindigo material is not a foreign concept, with both fluorinated ${ }^{64-66}$ and chlorinated ${ }^{67}$ derivatives reported in the literature. Fluorination is by far the most popular, highlighted by several publications within the last few years, but requires a fluorinated precursor to the base isoindigo core. ${ }^{66}$ On the other hand, the chlorination reaction offers the advantage of being accessible onto a previously synthesized and alkylated isoindigo core unit.

In this structure chlorination occurs primarily at the $5,5^{\prime}$ positions, directed to the ortho position by bromine substituent of $\mathbf{O c t}_{-\mathrm{IIBr}_{2}}$ and away from the position nearest the amido nitrogen. This selectivity is different from fluorinations which
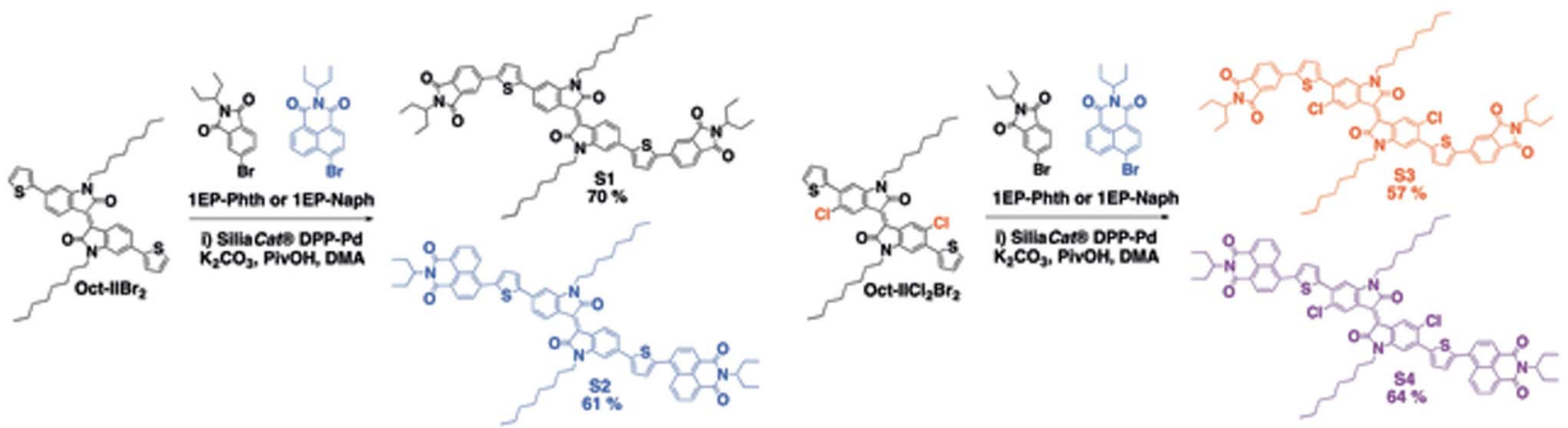

Scheme 1 Synthesis of isoindigo small molecules S1-4 (i) 2.2 eq. of 1EP-Phth or 1EP-Naph, 5 mol\% SiliaCat巴 DPP-Pd, 30 mol\% PivOH, and 2.5 eq. $\mathrm{K}_{2} \mathrm{CO}_{3}, 80^{\circ} \mathrm{C}$ for 16 hours. 
a)
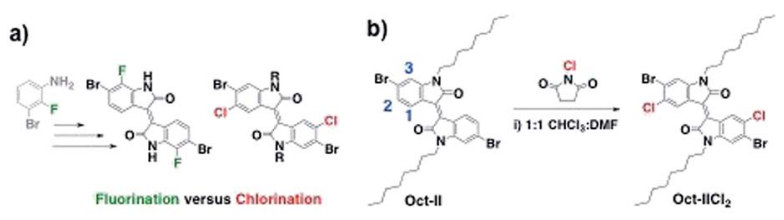

c)

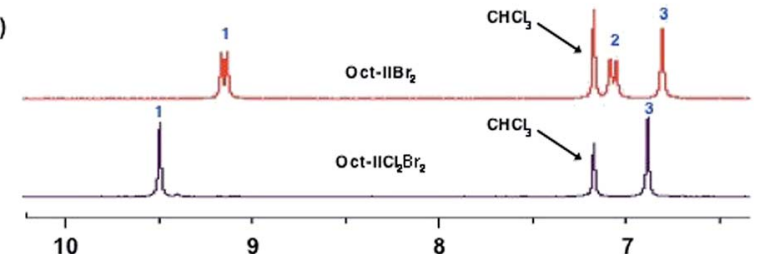

Fig. 2 (a) Fluorinated and chlorinated isoindigo materials (b) chlorination of Oct- $\mathrm{IBr}_{2}$ (i) 2.0 eq. of NCS, $70{ }^{\circ} \mathrm{C}$ for 16 hours and (c) ${ }^{1} \mathrm{H} \mathrm{NMR}$ spectra of the aromatic region shows the disappearance of 2 illustrating full conversion to the chlorinated precursor Oct- $\mathrm{ICl}_{2} \mathrm{Br}_{2}$

typically occur at the $7,7^{\prime}$ due to the ortho-directing groups $-\mathrm{Br}$ and $-\mathrm{NH}_{2}$ of the 3-bromoaniline precursor (Fig. 2a). The electrophilic chlorination of isoindigo with $\mathrm{N}$-chlorosuccinimide (NCS) has been previously reported for the synthesis of polymeric materials, ${ }^{67}$ but until now has not been exploited in a molecular framework (Fig. 2b). Although not exclusively selective to the $5,5^{\prime}$ position in the presence of any excess NCS, the use of exact stoichiometry, 2.0 equivalents, results in nearly full conversion to the chlorinated product (Fig. 2c). The subsequent work up and purification of the chlorinated isoindigo core was straightforward. The reaction mixture was concentrated under reduced pressure and the product isolated by filtration, washing with $\mathrm{H}_{2} \mathrm{O}$ and $\mathrm{MeOH}$. This was followed by dissolution in $\mathrm{CH}_{2} \mathrm{Cl}_{2}$ and precipitation into pentanes to yield a dark redpurple solid $(0.58 \mathrm{~g}, 87 \%)$.

In a similar protocol to that outlined for the synthesis of Oct$\mathbf{I I T h}_{2}$, the chlorinated isoindigo product was flanked with thiophene bridging units through a SiliaCat ${ }^{\circledR}$ DPP-Pd catalyzed and microwave-assisted Stille reaction. Again, benefitting from the use of a heterogeneous catalyst, the work up of final product was facile. Oct- $\mathbf{I I C l}_{\mathbf{2}}$ was isolated from the catalyst by vacuum filtration and the solvent removed under reduced pressure to yield a dark purple-brown solid, which was thoroughly washed with pentanes to remove residual impurities, and did not require purification by flash column chromatography $(0.48 \mathrm{~g}, 88 \%)$.

Isoindigo derivative $\mathbf{S 3}$ and $\mathbf{S 4}$ were both synthesized from the chlorinated precursor material Oct-IICl $\mathbf{l}_{2}$ through the same direct heteroarylation protocol outlined previously for $\mathbf{S 2}$. The synthesis of S3 occurred through the coupling between the chlorinated isoindigo molecular core and 1EP-Phth, while the synthesis of S4 made use of 1EP-Naph as the terminal acceptor. Both products were isolated and purified in the same manner as S2, and yielded dark black solids ( $0.23 \mathrm{~g}, 57 \%$ and $0.22 \mathrm{~g}, 64 \%$ respectively).

\section{Characterization}

The structure-property relationships that manifest from the structural evolution of S1 were closely analyzed by UV/visible spectroscopy (UV/vis), cyclic voltammetry (CV), and differential scanning calorimetry (DSC). Table 1 summarizes the observed properties of S1-4 and the results will be discussed in the following section.

\subsection{Optical properties}

The optical absorption profiles of isoindigo derivatives S1-4 were collected by UV/visible absorption spectroscopy (UV/vis), solution and thin-film spectra are shown in Fig. 3. In accordance with our previous publication, each small molecule was subject to thermal and solvent vapour post-deposition annealing to investigate their influence on thin-film absorption profiles. Individual absorption profiles under these conditions can be found in the ESI. $\dagger$

The solution absorption spectra of small molecule isoindigo derivatives S1-4 have two distinct features, a low-energy absorption band at approximately $570 \mathrm{~nm}$ and a high-energy band at approximately $450 \mathrm{~nm}$. In comparing the relative intensities of these two bands a significant variance is observed with each structural modification. To emphasize this noteworthy change in the low-energy HOMO to LUMO transition, the absorption spectra have been normalized to the high-energy band at $450 \mathrm{~nm}$.

As we substitute naphthalimide for phthalimide in $\mathbf{S 2}$, we see a sizeable decrease in the intensity of this band; which becomes reduced further in $\mathbf{S} \mathbf{3}$ when substituting a chlorinated isoindigo core, with S4 displaying the largest drop in this intensity. This suggests that the successive modifications to the original isoindigo framework have a direct influence on the intensity, and therefore the probability of these orbital transitions.

The source of these observed differences is proposed to originate from the sterically hindered co-planarity of the framework, which translates into inefficient orbital mixing of the donor and acceptor components within the structure. Introducing a twist to the $\pi$-conjugated backbone will disrupt the extent of $\pi$-orbital delocalization and consequently hinder electronic transitions. We have previously discussed how naphthalimide for phthalimide substitution at the terminal acceptor can have this effect, ${ }^{60}$ and thus can be correlated with the observed spectra. Similarly, the integration of chlorine atoms can also disrupt planarity; however, the influence on orbital transitions is more pronounced in this case as it directly involves the isoindigo core where the LUMO is largely localized. Therefore it is rational that $\mathbf{S 4}$, which incorporates both of these sterically demanding modifications, has the most restricted low-energy transition.

Thin-film UV/vis spectra have provided additional insight towards the influence of the structural evolution on optical properties. In the solid state, each absorption profile is redshifted, consistent with similar dyes in the literature. ${ }^{\mathbf{6 8 , 6 9}}$ The red-shift is more pronounced for the chlorinated derivatives $\mathbf{S 3}$ and S4, suggesting that the chlorine atoms play a role in the solid state self-assembly of these materials. Similar to the solution profiles, a reduced low energy transition is observed for each subsequent structural modification. Further evidence pertaining to solid-state self-assembly is manifested in the 
Table 1 A summary of the optical, electronic and thermal properties of isoindigo small molecules S1-4

\begin{tabular}{|c|c|c|c|c|c|c|c|c|}
\hline Small molecule & $\operatorname{Abs}_{\max }{ }^{a}(\mathrm{~nm})$ & $\operatorname{Abs}_{\text {onset }}{ }^{a}(\mathrm{~nm})$ & $\mathrm{IE}^{b}(\mathrm{eV})$ & $\operatorname{HOMO}^{c}(\mathrm{eV})$ & $\operatorname{LUMO}^{c}(\mathrm{eV})$ & Band gap $^{c}(\mathrm{eV})$ & $T_{\mathrm{m}}\left({ }^{\circ} \mathrm{C}\right)$ & $T_{\mathrm{c}}\left({ }^{\circ} \mathrm{C}\right)$ \\
\hline S1 & 455 & 708 & 5.7 & -5.58 & -3.67 & 1.81 & 257 & 210 \\
\hline S2 & 450 & 709 & 5.6 & -5.53 & -3.70 & 1.83 & 274 & - \\
\hline S4 & 482 & 711 & 5.7 & -5.61 & -3.73 & 1.88 & - & - \\
\hline
\end{tabular}

${ }^{a}$ Estimated from thin-film absorption profile. ${ }^{b}$ Estimated from ultraviolet photoemission spectroscopy. ${ }^{c}$ Estimated from cyclic voltammetry measurements with ferrocene as the internal reference.

appearance of fine structure, which can be seen as a ripple in the profiles of $\mathbf{S} 1$ and $\mathbf{S} 3$ between 500 and $\mathbf{7 0 0 ~} \mathrm{nm}$ to suggest an ordered morphology. On the other hand, the profiles of $\mathbf{S} 2$ and S4 display smoother profiles, which is rationalized as a consequence of the phthalimide for naphthalimide substitution where it is expected that the materials will be less crystalline, and therefore represent a less ordered solid-state assembly.

\subsection{Electrochemical properties}

The electrochemical properties of isoindigo derivatives S1-4 were analyzed by cyclic voltammetry (CV), shown in Fig. 4, and ultraviolet photoemission spectroscopy (UPS), shown in the ESI. $\uparrow$ Individual cyclic voltammograms including the internal reference ferrocene can be found in the ESI. $\dagger$

With S1 as a point of comparison, the replacement of phthalimide with naphthalimide terminal acceptors (S2) is not accompanied by any significant changes to the oxidation or reduction potentials. On the other hand, the most evident change is seen in the reduction profile where naphthalimide extends the one-electron double reduction of phthalimide to a reversible triple reduction. Not dissimilar to $\mathrm{PC}_{61} \mathrm{BM},{ }^{70}$ this suggests that $\mathbf{S} 2$ has the capability to reversibly accept more than just one electron, beneficial for its role in separating charge in a photovoltaic cell.

The effect of the chlorination of isoindigo on the electrochemical properties of $\mathbf{S} \mathbf{3}$ was evaluated in comparison to $\mathbf{S} \mathbf{1}$ and displayed a similar voltammogram trace. In this case, there exists a shift in the oxidation and reduction potentials to more positive voltages, most prominent in the onset of oxidation. Consistent with the chlorination previously reported in the literature, this suggests that upon the substitution of chlorine for hydrogen, a stabilization of the energy levels occurs as a
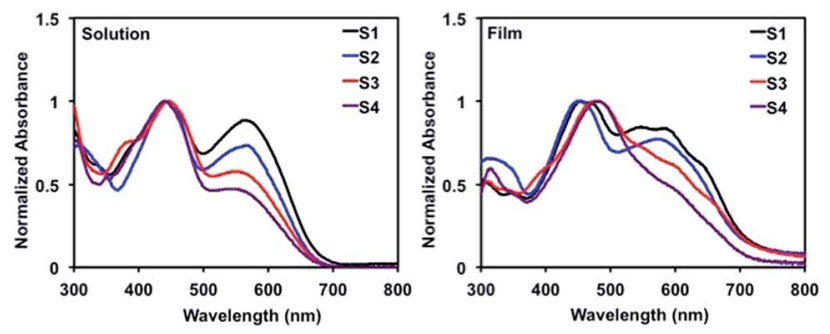

Fig. 3 Normalized solution and thin-film absorption profiles of isoindigo non-fullerene acceptors S1-4. Spectra obtained from $1.0 \mathrm{w} / \mathrm{v} \%$ solutions in $\mathrm{CHCl}_{3}$ and cast onto glass substrates. result of the integration of a more electronegative atom to the framework. As expected, $\mathbf{S 4}$ benefits from both of these structural modifications and exhibits both a reversible triple reduction and an overall stabilization of the energy levels.

UPS measurements show that the ionization energy is slightly affected by each structural modification. In the thin film, $\mathbf{S 1}$ has an ionization energy of approximately $5.7 \mathrm{eV}$, which is lowered to $5.6 \mathrm{eV}$ following naphthalimide substitution (S2) and raised to $5.8 \mathrm{eV}$ upon chlorination of the isoindigo core (S3). Following this trend, $\mathbf{S 4}$ was shown to have the same ionization potential as $\mathbf{S 1}, 5.7 \mathrm{eV}$, as the two structural modifications have an offsetting influence.

These small changes to the electrochemical properties of S14 serves to highlight the ability of the synthetic chemist to systematically tune the energy levels of a given molecular system through intricate structural modification of a functional framework.

\subsection{Thermal properties}

The thermal properties isoindigo derivatives S1-4 were monitored by differential scanning calorimetry (DSC), the melting and crystallization transitions are shown in Fig. 5. Individual DSC thermograms can be found in the ESI. $\dagger$

Consistent with our previous work, the naphthalimide for phthalimide substitution was accompanied by a complete loss
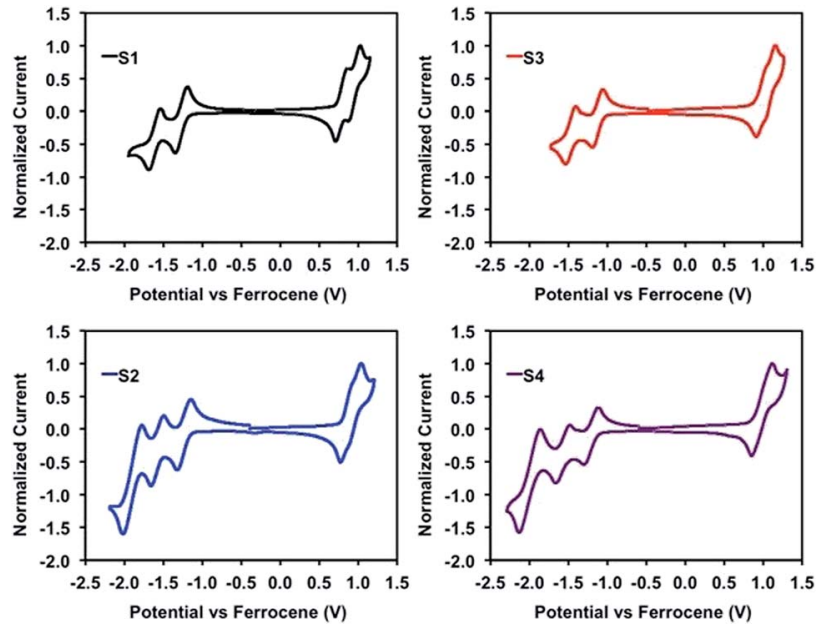

Fig. 4 Reduction and oxidation traces of isoindigo non-fullerene acceptors S1-4. Cyclic voltammogram obtained in $\mathrm{CH}_{2} \mathrm{Cl}_{2}$ solution under an $\mathrm{N}_{2}$ atmosphere with a sweep rate of $100 \mathrm{mV} \mathrm{s}^{-1}$. 

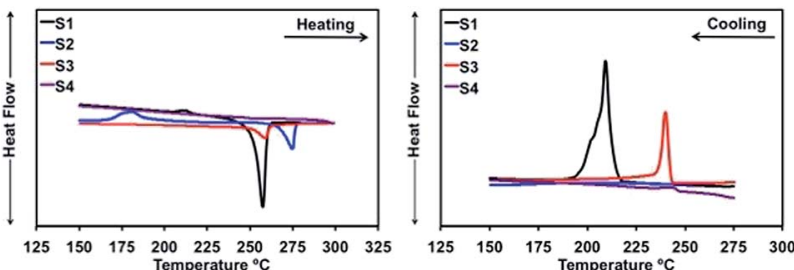

Fig. 5 Thermal transitions of isoindigo non-fullerene acceptors S1-4. DSC thermograms obtained from scanning at $10^{\circ} \mathrm{C} \mathrm{min}{ }^{-1}$ from 50 to $300^{\circ} \mathrm{C}$.

of the crystallization transition for S2, confirming our notion that naphthalimide substitution could significantly reduce the crystallinity of the small molecule acceptor S1. On the other hand, the influence of a chlorinated isoindigo core, S3, was not as pronounced. The thermogram displayed both melting and crystallization transitions, albeit with crystallization occurring at a higher temperature than that observed for S1. The combination of naphthalimide and a chlorinated isoindigo core, S4, not only suppressed crystallization but also revealed a high thermal stability with no melting transition detected within the thermal the range of our experiment.

\subsection{Computational analysis}

The use of computational methods to investigate the theoretical optical and electronic properties of small molecules has been well-documented..$^{71-73}$ We have previous demonstrated how density functional theory (DFT) can be used to screen a variety small molecules and highlight promising structures to pursue synthetically. ${ }^{74}$ In this work the molecular geometries were optimized at the B3LYP/6-31G(d,p) level of theory with timedependent (TD) calculations completed using TD-B3LYP/6$31 \mathrm{G}(\mathrm{d}, \mathrm{p})$ to predict the optical and electronic properties of the molecules. For further details on our DFT methods we refer the reader to our previous work. ${ }^{74}$ Summaries of the results are represented in Fig. 6 with complete computational data included in the ESI. $\dagger$

The optimized structures of S1-4 (Fig. 6a) depict the gradual increase in non-planarity with each modification. Considering the planar S1 structure as a point of comparison, naphthalimide for phthalimide substitution (S2) was shown to induce a drastic $24^{\circ}$ increase in the torsion angle between the thiophene bridging unit and the terminal acceptor $\left(23^{\circ}\right.$ to $\left.47^{\circ}\right)$ as a result of the increased steric demand of the naphthalimide terminal acceptor. Similar deviations from planarity were observed for the inclusion of chlorine atoms to the isoindigo core (S3). In this case we focused on the torsion angle between the thiophene bridging unit and the isoindigo core, which results in a smaller, yet still significant, $13^{\circ}$ increase $\left(22^{\circ}\right.$ to $\left.35^{\circ}\right)$. This value is nearly identical to that reported for the chlorinated isoindigo polymer PCII2T, ${ }^{67}$ where the increase in dihedral angle is attributed to the larger atomic radii of a chlorine atom in comparison to hydrogen. This reveals a unique method to alter both sterics and electronic configuration through the chlorination of organic materials. As expected, these torsion angles were conserved in the $\mathbf{S 4}$ structure, which depicted a considerably non-planar optimized structure. Evidently, the increased steric demands of both the naphthalimide terminal acceptor and the integrated chlorine atoms have a pronounced influence on the backbone planarity of these isoindigo materials, which could account for differences in materials properties and performance.

Comparing the predicted energy levels of S1-4 (Fig. 6b) serves to highlight the influence of each structural evolution and the trends that exist. While DFT calculations do not accurately predict HOMO/LUMO energies, trends in these energies between closely related materials can be reliably computed. Introducing naphthalimide terminal acceptors (S2) has a negligible influence on the predicted LUMO energy level of S1 (3.09 eV versus $3.10 \mathrm{eV}$ ) but, as expected, incorporating chlorine atoms (S3) has a much greater effect on the LUMO energy level, bringing it down $0.21 \mathrm{eV}$ to $-3.30 \mathrm{eV}$. Again these influences are preserved in the $\mathbf{S 4}$ structure, which depicts the most stabilized energy levels of all isoindigo derivatives at $-3.33 \mathrm{eV}$.

Analysis of the predicted orbital transitions of S1-4 (Fig. 6c) can help reinforce our rational for the differences observed in the UV/vis optical absorption profiles of the four isoindigo materials. The gradual decrease in intensity observed in each subsequent structural modification fuels the proposition that the decline in HOMO to LUMO transitions could be due to inefficient orbital mixing between the donor and acceptor components in the structure as a result of decreased coplanarity. The orbital surface depictions also support this conclusion; they display an increasingly localized LUMO orbital system, exposing the development of a truncated $\pi$-conjugated system as a result of the twist in the backbone. If we consider the observed UV/vis profiles, a small reduction in intensity was observed for naphthalimide substitution - this agrees with the predicted orbital depictions which show that even the planar original structure does not offer a delocalized $\pi$-system that extends to include the terminal acceptor. The reduced intensity is more notable with the introduction of chlorine to the structure. This relates to the disrupted co-planarity between the isoindigo core and the thiophene bridging unit, and the resultant highly localized $\pi$-system at the isoindigo core. This limited delocalization could be responsible for deterred HOMO to LUMO transitions and consequently reduced intensity.

Another transition of note is the increased contribution of the HOMO to LUMO+1 and LUMO+2 in the chlorinated derivatives. The LUMO+1 and LUMO+2 orbital surfaces are highly localized at the terminal acceptor units (see ESI $\dagger$ ). This feature of the chlorinated derivatives is rationalized to emerge as a result of the aforementioned encumbered HOMO to LUMO transitions, and thus increases the probability for orbital transition to these higher LUMO levels.

To summarize, the computational analysis of this series of isoindigo materials has proven to be crucial to the understand the structure-property relationships within this series of molecules. Both structural features, be it a chlorine atom at the isoindigo core or naphthalimide as the terminal acceptor, exert a significant influence on the backbone planarity of the structure. These alterations to the molecular geometry lead to 

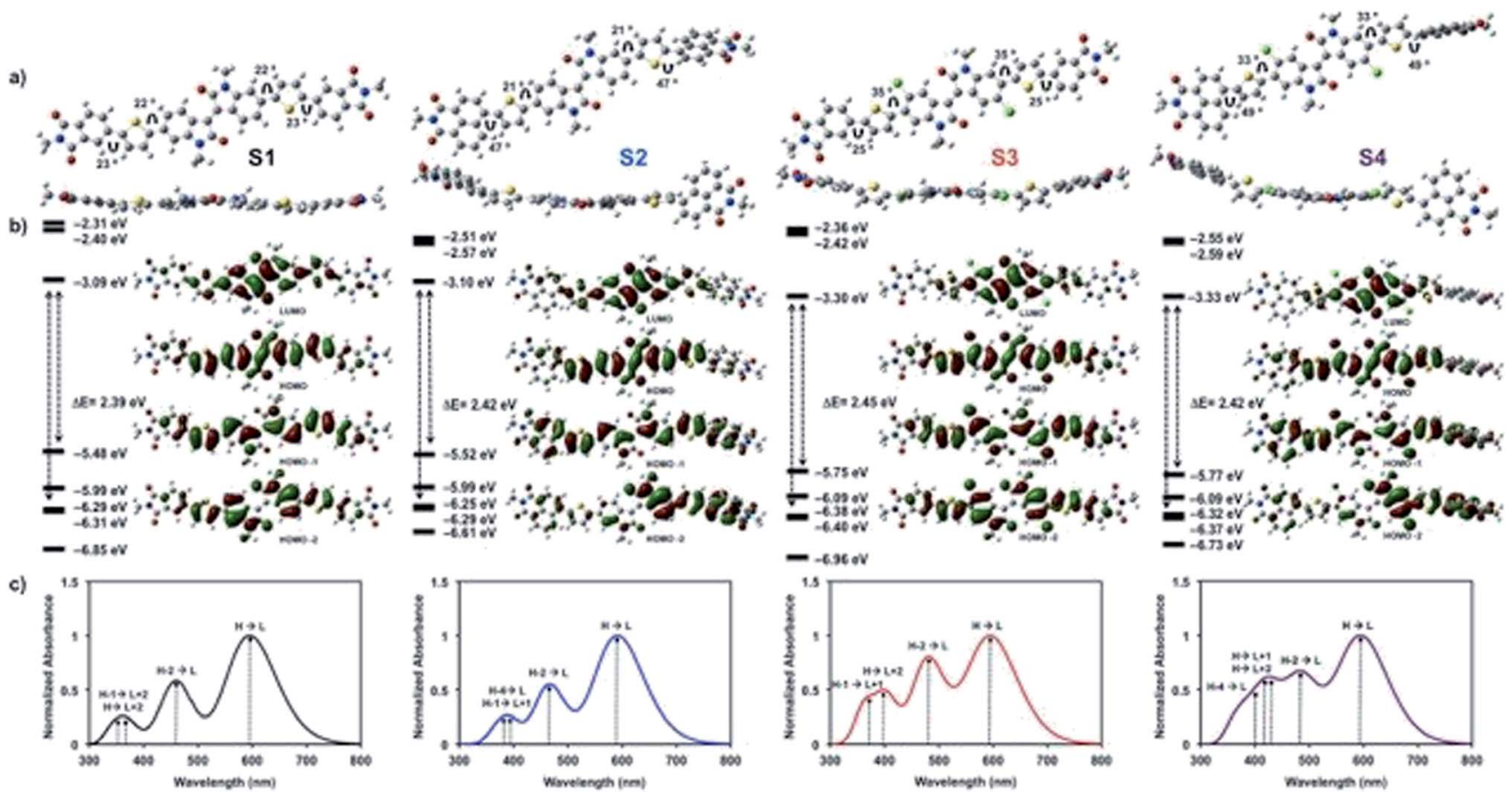

Fig. 6 Summary of the computational analysis for S1-S4 (a) optimized structure (b) predicted energy levels and orbital depictions and (c) predicted orbital transitions.

significant differences in the predicted orbital transitions. When extended to the experimental absorption profiles, the computational analysis offers an explanation for the observed decrease in intensity of the low-energy absorption maxima where the inefficient orbital mixing resulting from a twisted structure perturbs this normally strong transition in planar molecules.

\section{Device performance}

While these $\pi$-conjugated isoindigo small molecules can be applicable to various organic electronic applications, our interest is primarily focused on the development of alternatives to fullerene acceptors in OPV. To explore the influence of structural evolution on the performance of S1-4 as nonfullerene acceptors, proof-of-concept photovoltaic devices were fabricated in the same manner as our previous publications involving this framework. ${ }^{51,75}$ Our choice of inverted architecture: ITO/ZnO/p-DTS(FBTTh ) $_{2}: \mathbf{S X} / \mathrm{MoO}_{3} / \mathrm{Ag}$ (Fig. 7) is based on our investigation of $\mathbf{S 1}$ where an inverted architecture demonstrated a $90 \%$ increase in efficiency with the best cells reaching $1.0 \%$ PCE. ${ }^{75}$ The active layers were composed of $1: 1$ weight ratios and cast from $2.0 \mathrm{wt} / \mathrm{v} \%$ solutions in chlorobenzene (CB) with $0.4 \mathrm{v} / \mathrm{v} \%$ DIO additive. We maintained the same device fabrication procedure with regards to architecture and active layer casting conditions in order to assess how our two design criteria (reduced planarity and increased electron affinity) affected device performance. The performance of S1-4 in OPV devices has been summarized in Table 2 with best cell currentvoltage curves shown in Fig. 8. Complete current-voltage curves for each isoindigo derivative can be found in the ESI. $\dagger$
External quantum efficiency (EQE) spectra of devices with $p$-DTS(FBTTh $)_{2}$ :SX active layer compositions displayed photocurrent generation beginning at approximately $750 \mathrm{~nm}$ and extending past $400 \mathrm{~nm}$. The greatest efficiency was recorded in the low-energy region with major contribution from the donor material $\boldsymbol{p}$-DTS(FBTTh $\left.\mathbf{H}_{2}\right)_{2}$, with the major contribution from the acceptor materials S1-4 being the broad spectral coverage. EQE spectra and device parameters can be found in the ESI. $\dagger$

Considering our previous results, devices were tested as-cast with no post-deposition annealing of the active layers. The performance of $\mathbf{S} \mathbf{1}$ was consistent with the metrics attained in our previous report for its optimization in an inverted architecture. ${ }^{75}$ Naphthalimide for phthalimide substitution, $\mathbf{S 2}$, was anticipated to improve thin-film morphology and the resultant device performance based on reducing the tendency for crystallization observed in S1. Unfortunately, this did not manifest in devices, which instead showed in a significant decrease in efficiency $(0.38 \%$ versus $1.01 \%)$, with current density $\left(U_{\mathrm{sC}}\right)$ roughly half of that reached for $\mathbf{S 1}\left(-1.29 \mathrm{~mA} \mathrm{~cm}{ }^{-2}\right.$ versus $\left.-2.60 \mathrm{~mA} \mathrm{~cm}^{-2}\right)$. The

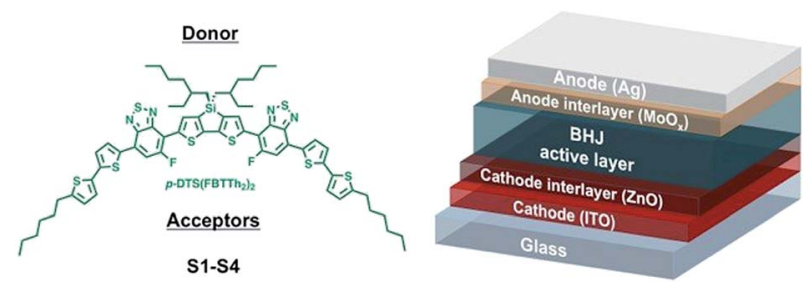

Fig. 7 Schematic of the inverted device architecture used in our experiments and the chemical structure of the donor small molecule $p$-DTS $\left(\text { FBTTh }{ }_{2}\right)_{2}$. 
Table 2 Summary of the OPV device performance of non-fullerene acceptors S1-S4

\begin{tabular}{|c|c|c|c|c|}
\hline Small molecule & $V_{\mathrm{OC}}{ }^{a}(\mathrm{~V})$ & $J_{\mathrm{SSC}}{ }^{a}\left(\mathrm{~mA} \mathrm{~cm}{ }^{-2}\right)$ & $\mathrm{FF}^{a}$ & $\operatorname{PCE}^{a}(\%)$ \\
\hline S1 & $0.91(0.92)$ & $-2.52(-2.60)$ & $0.41(0.42)$ & $0.93(1.01)$ \\
\hline S2 & $0.68(0.68)$ & $-1.15(-1.29)$ & $0.40(0.44)$ & $0.31(0.38)$ \\
\hline S3 & $0.84(0.90)$ & $-0.89(-1.23)$ & $0.44(0.41)$ & $0.33(0.46)$ \\
\hline S4 & $0.82(0.87)$ & $-2.94(-3.39)$ & $0.44(0.42)$ & $1.07(1.24)$ \\
\hline $\mathbf{S} \mathbf{4}^{* b}$ & 0.87 & -5.27 & 0.42 & 1.93 \\
\hline
\end{tabular}

${ }^{a}$ Average (best PCE) cell. ${ }^{b}$ *Best performance cell to date.

open circuit voltage $\left(V_{\mathrm{OC}}\right)$ also exhibited a substantial decline $(0.68 \mathrm{~V}$ versus $0.92 \mathrm{~V})$. Based on these results, the issue that plagues device performance is likely related to the compatibility of the active layer materials, presumably poor molecular mixing, leading to inefficient charge separation and transport.

The chlorination of isoindigo, $\mathbf{S 3}$, slightly improved on the performance of S2, but remained well below the efficiency of S1 $(0.46 \%$ versus $1.01 \%) . J_{\mathrm{SC}}$ was again limited in comparison to $\mathbf{S 1}$ $\left(-1.23 \mathrm{~mA} \mathrm{~cm}^{-2}\right.$ versus $\left.-2.60 \mathrm{~mA} \mathrm{~cm}{ }^{-2}\right)$, but displayed a similar $V_{\mathrm{OC}}(0.90 \mathrm{~V}$ versus $0.92 \mathrm{~V})$. In the process of casting the active layer under our outlined conditions, it became evident that the difficulty in forming uniform thin-films plagued the performance of S3 (see ESI $\dagger$ ). When cast from chlorobenzene the active layer blend of $\boldsymbol{p}$-DTS(FBTTh $\left.{ }_{2}\right)_{2}: \mathbf{S 3}$ led to the formation of non-uniform thin-films with large cloudy patches, in many cases leading to shorted cells (images of thin-film devices shown in the ESI $\dagger$ ). Due to the large substrate size (18 cells per substrate) the performance of $\mathbf{S} \mathbf{3}$ was highly variable and was dependent on the nature of the thin film at each individual cell, but even the best cell could not match $\mathbf{S 1}$.

The combination of a chlorinated isoindigo core and naphthalimide end caps finally culminated in a derivative that was better than the predecessor S1. The best performing cell of S4 reached $1.24 \%$ PCE, with an increase in $J_{\mathrm{SC}}\left(-3.39 \mathrm{~mA} \mathrm{~cm}{ }^{-2}\right.$ versus $\left.2.60 \mathrm{~mA} \mathrm{~cm}^{-2}\right)$ and only a slight decrease in $V_{\mathrm{OC}}(0.87 \mathrm{~V}$ versus $0.92 \mathrm{~V}$, LUMO energies $-3.73 \mathrm{eV}$ versus $-3.67 \mathrm{eV})$. S4 suffered from the same film-forming problems as $\mathbf{S 3}$, and led to

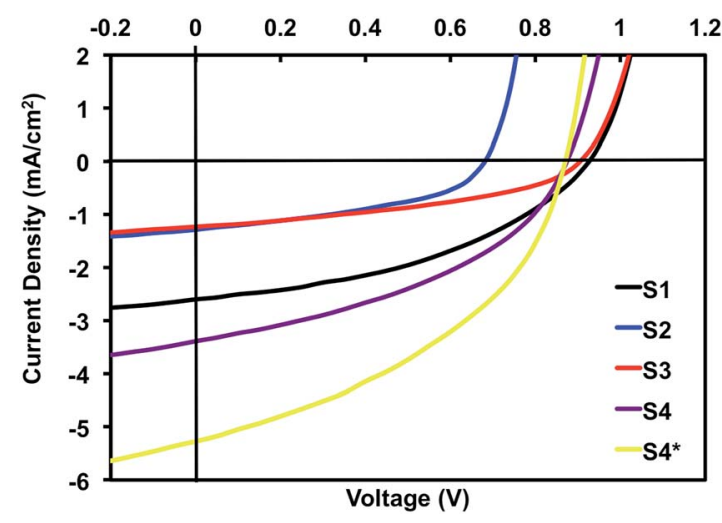

Fig. 8 Current-voltage curves for the best performing cells of S1-4. S4* denotes best performing cell to-date and serves to highlight the potential of this material for further optimization. highly variable performance metrics, which undoubtedly curbed our efficiencies.

AFM images were obtained to investigate the thin-film morphology of S1-S4 OPV devices, the images can be found in the ESI. $\dagger$ Unfortunately the AFM imaging of the active layer devices did not bring any clarity to the situation, and displayed only subtle changes to the thin-film microstructure with no clear indication of any major differences.

The difficulty associated with processing uniform thin-films is often overlooked but undoubtedly plays a crucial role in the overall performance of these materials. The performance of the chlorinated isoindigo derivatives $\mathbf{S} \mathbf{3}$ and $\mathbf{S 4}$ is visibly plagued by poor film-forming properties when cast from chlorobenzene and thus warranted further exploration. We considered several different processing solvents, $o$-dichlorobenzene did not wet the substrate, but uniform thin-films were manageable when cast from solutions of chloroform or $1: 4$ chloroform : chlorobenzene, although the resulting device performance was quite poor, demonstrating that despite the lack of uniformity, films cast from chlorobenzene generally led to the best device performance. Throughout the investigation of the different processing solvents we continued to look at casting from chlorobenzene. With numerous substrates to choose from, we selected those that visually appeared to be the most uniform for device incorporation. From this selection, our champion cell was able to reach $1.93 \%$ (versus $1.01 \%$ for $\mathbf{S 1}$ ) this current-voltage trace is shown in Fig. 8 $(\mathbf{S 4} *)$. This remarkable rise in performance is largely attributed to a substantial increase in $J_{\mathrm{SC}}\left(5.31 \mathrm{~mA} \mathrm{~cm}^{-2}\right.$ versus $\left.2.60 \mathrm{~mA} \mathrm{~cm}{ }^{-2}\right)$ undoubtedly a result of a more favourable thin-film formation, and serves to highlight the potential for additional performance increases with a more favourable thin-film morphology.

Considering the inherent high $V_{\mathrm{OC}}$ of these isoindigo materials, the large increase in $J_{\mathrm{SC}}$ that accompanied our champion S4 cell suggests that this material can adopt a more favourable thin-film morphology for device operations than any of its predecessors. It appears that the twisted nature of the $\mathbf{S 4}$ backbone could be responsible for this improved performance, not unlike that which has been documented for some of the recent high-performance PDI acceptors discussed beforehand.

\section{Conclusions}

The importance of a versatile structure cannot be understated, this key design feature enabled the adaptability of our original isoindigo framework to evolve through synthetic modification and reach improved efficiencies.

The targeted structural modifications of $\mathbf{S 1}$ were selected based on the deficiencies that most likely led to its restricted OPV performance: the tendency to over-crystallize, and its moderate electron-deficient character. We designed three new materials to address these issues: (1) a naphthalimide terminal acceptors to reduce backbone planarity and disrupt crystallization, (2) a chlorinated isoindigo core to increase electronaccepting character and (3) the combination of both these modifications into one framework.

The structural evolution of the isoindigo-based nonfullerene acceptor $\mathbf{S} 1$ culminated in a new material that was 
greater than its predecessors. Although no single modification to the core or terminal acceptor outperformed the original, the combination of both structural alterations within the same small molecule led to a new derivative that was able to reach greater efficiencies, with the highest performance to date reaching $1.93 \%$ PCE.

Despite the seemingly inherently poor film-forming properties of $\mathbf{S 4}$ from chlorobenzene solutions, the potential to reach even higher performance metrics exists, but requires further investigation of the active layer processing conditions and optimization of device fabrication, which is an on-going interest in our research groups. Meanwhile, synthetically we are exploring other structural modifications of the $\mathbf{S 4}$ framework to expand our understanding of isoindigo-based materials.

\section{Experimental section}

\subsection{General synthetic details}

Preparations were carried out on a bench top or under an atmosphere of dry, $\mathrm{O}_{2}$-free $\mathrm{N}_{2}$ via Schlenk line techniques and/ or an Innovative Technology Inc. $\mathrm{N}_{2}$ atmosphere glove box. Purification by flash column chromatography was performed using a Biotage ${ }^{\circledR}$ Isolera flash system.

\subsection{Materials}

The isoindigo starting materials, 6-bromoisatin and 6-bromo-2oxindole were purchased from Ontario Chemicals Inc. Heterogeneous catalyst SiliaCat ${ }^{\circ}$ DPP-Pd was purchased from SiliCycle. All other materials were purchased from either SigmaAldrich or TCI America. The small molecule donor, p-DTS(FBTTh $)_{2}$ was purchased from 1-Material.

\subsection{Precursor synthetic procedure}

Isoindigo precursors and $\mathbf{S 1}$ were synthesized according to previously reported literature procedures. ${ }^{51}$

Synthesis of 4-bromo-1-(ethylpropyl)naphthalimide (1EPNaph). The following synthesis was based on a modified literature procedure. ${ }^{76} \mathrm{~A} 10-20 \mathrm{~mL}$ glass vial was loaded with 4-bromo1,8-naphthalic anhydride $(1.01 \mathrm{~g}, 3.65 \mathrm{mmol})$ and 1-ethylpropylamine $(0.60 \mathrm{~g}, 6.88 \mathrm{mmol})$ in ethanol $(10 \mathrm{~mL})$. The vial was sealed with a silicone cap set to stir in an oil bath at $110{ }^{\circ} \mathrm{C}$ for 16 hours. The reaction mixture was subsequently removed from heat and precipitated into vigorously stirring $\mathrm{H}_{2} \mathrm{O}(400 \mathrm{~mL})$. The product was isolated by vacuum filtration, recrystallized from iPrOH and dried in vacuo to yield an off-white solid (0.98 g, $2.83 \mathrm{mmol}, 78 \%$ yield).

${ }^{1} \mathrm{H} \mathrm{NMR}\left(\mathrm{CDCl}_{3}\right) . \delta 8.65\left(\mathrm{~d}, 1 \mathrm{H},{ }^{1} J_{\mathrm{H}-\mathrm{H}}=7 \mathrm{~Hz}\right), 8.57\left(\mathrm{~d}, 1 \mathrm{H},{ }^{1} J_{\mathrm{H}-\mathrm{H}}\right.$ $=9 \mathrm{~Hz}), 8.41\left(\mathrm{~d}, 1 \mathrm{H},{ }^{1} J_{\mathrm{H}-\mathrm{H}}=8 \mathrm{~Hz}\right), 8.05\left(\mathrm{~d}, 1 \mathrm{H},{ }^{1} J_{\mathrm{H}-\mathrm{H}}=8 \mathrm{~Hz}\right)$, $7.86\left(\mathrm{~d}, 1 \mathrm{H},{ }^{1} J_{\mathrm{H}-\mathrm{H}}=7 \mathrm{~Hz},{ }^{2} J_{\mathrm{H}-\mathrm{H}}=1 \mathrm{~Hz}\right), 5.04(\mathrm{~m}, 1 \mathrm{H}), 2.23(\mathrm{~m}$, $2 \mathrm{H}), 1.92(\mathrm{~m}, 2 \mathrm{H}), 0.91(\mathrm{t}, 6 \mathrm{H})$.

${ }^{13} \mathrm{C} \mathrm{NMR}\left(\mathrm{CDCl}_{3}\right) . \delta 132.9,132.0,131.2,131.1,130.5,129.9$, 129.2, 128.1, 57.6, 25.0, 11.3. Theoretical: 15 peaks, experimental: 11 peaks.

MS (APCI-TOF). $m / z$ 346.0. Calcd 346.2.

Synthesis of $6,6^{\prime}$-bis(thiophen-5,2-diyl)bis(2-(1-ethylpropyl) naphthalimide)-1,1'-di(octyl)isoindigo (S2). A 2-5 mL glass vial was loaded bench top with 6,6'-di(thiophen-2-yl)-1,1'-di(octyl) isoindigo (0.25 g, $0.38 \mathrm{mmol})$, 4-bromo-1-(ethylpropyl) naphthalimide $(0.32 \mathrm{~g}, 0.92 \mathrm{mmol})$, potassium carbonate (0.13 g, $0.94 \mathrm{mmol})$, SiliaCat ${ }^{\circledR}$ DPP-Pd (0.08 g, $\left.5 \mathrm{~mol} \%\right)$, pivalic acid $(0.02 \mathrm{~g}, 0.2 \mathrm{mmol})$ and DMA $(3 \mathrm{~mL})$. The purple reaction mixture was sealed with a silicone cap and stirred in an oil bath at $80{ }^{\circ} \mathrm{C}$ for 16 hours. The resultant black reaction mixture was dissolved in $\mathrm{CH}_{2} \mathrm{Cl}_{2}(100 \mathrm{~mL})$ and filtered through silicagel to isolate from the heterogeneous catalyst with thorough washing with dichloromethane $(300 \mathrm{~mL})$. The filtrate was concentrated under reduced pressure and was liquid loaded on a SiliaSep ${ }^{\text {TM }} 25 \mathrm{~g}$ cartridge and purified by flash column chromatography with dichloromethane as the eluent. The final product can be isolated by filtration from $\mathrm{MeOH}$, washing with hot iPrOH to yield a purple-black solid (0.28 g, $0.24 \mathrm{mmol}, 63 \%$ yield).

${ }^{1} \mathrm{H} \mathrm{NMR}\left(\mathrm{CDCl}_{3}\right) . \delta 9.27\left(\mathrm{~d}, 2 \mathrm{H},{ }^{1} J_{\mathrm{H}-\mathrm{H}}=8 \mathrm{~Hz}\right), 8.68(\mathrm{~m}, 6 \mathrm{H})$, $7.89\left(\mathrm{~d}, 2 \mathrm{H},{ }^{1} J_{\mathrm{H}-\mathrm{H}}=8 \mathrm{~Hz}\right), 7.81(\mathrm{~m}, 2 \mathrm{H}), 7.57\left(\mathrm{~d}, 2 \mathrm{H},{ }^{1} J_{\mathrm{H}-\mathrm{H}}=4\right.$ $\mathrm{Hz}), 7.38\left(\mathrm{~d}, \mathrm{ov}, 2 \mathrm{H},{ }^{1} J_{\mathrm{H}-\mathrm{H}}=4 \mathrm{~Hz}\right), 7.38\left(\mathrm{~d}, \mathrm{ov}, 2 \mathrm{H},{ }^{1} J_{\mathrm{H}-\mathrm{H}}=8 \mathrm{~Hz}\right)$, $7.05(\mathrm{~s}, 2 \mathrm{H}), 5.08(\mathrm{~m}, 2 \mathrm{H}), 3.87(\mathrm{t}, 4 \mathrm{H}), 2.28(\mathrm{~m}, 4 \mathrm{H}), 1.94(\mathrm{~m}, 4 \mathrm{H})$, $1.79(\mathrm{~m}, 4 \mathrm{H}), 1.46-1.28(\mathrm{~m}, 20 \mathrm{H}), 0.93(\mathrm{t}, 12 \mathrm{H}), 0.86(\mathrm{t}, 6 \mathrm{H})$.

${ }^{13} \mathrm{C} \mathrm{NMR}\left(\mathrm{CDCl}_{3}\right) . \delta 168.2,146.1,145.5,140.5,138.2,137.3$, 132.2 , 131.8, 130.6, 130.1, 129.7, 129.1, 128.5, 127.4, 125.1, 121.6, 119.4, 104.7, 57.5, 40.2, 31.8, 29.3, 29.2, 27.6, 27.1, 25.1, 22.6, 14.1, 11.3. Theoretical: 35 peaks, experimental: 29 peaks. MS (APCI-TOF). $\mathrm{m} / \mathrm{z}$ 1181.5. Calcd 1181.6.

$E A$. Calculated for $\mathrm{C}_{74} \mathrm{H}_{76} \mathrm{~N}_{4} \mathrm{O}_{6} \mathrm{~S}_{2}$ : C, 75.2; H, 6.5; N, 4.7. Found: C, 75.1; H, 6.3; N, 4.7.

Synthesis of $5,5^{\prime}$-dichloro-6, $6^{\prime}$-dibromo-1, $\mathbf{1}^{\prime}$-di(octyl)isoindigo (Oct- $\mathrm{IICl}_{2} \mathbf{B r}_{2}$ ). The following synthesis was based on a literature procedure. ${ }^{67}$ A $10-20 \mathrm{~mL}$ glass vial was loaded bench top with 6,6'-dibromo-1,1'-di(octyl)isoindigo (0.60 g, $0.93 \mathrm{mmol}$ ) and $N$-chlorosuccinimide $(0.25 \mathrm{~g}, 1.86 \mathrm{mmol})$. The contents were solubilized in a $1: 1$ mixture of $\mathrm{DMF}(7 \mathrm{~mL})$ and $\mathrm{CHCl}_{3}$ (7 mL), purged with $\mathrm{N}_{2}$ and sealed with a silicone cap. The reaction mixture was heated at $70{ }^{\circ} \mathrm{C}$ for 16 hours and subsequently filtered through silica-gel, washing with $\mathrm{CH}_{2} \mathrm{Cl}_{2}$ $(100 \mathrm{~mL})$ and concentrated under reduced pressure. The dark red solid was slurried in $\mathrm{H}_{2} \mathrm{O}$, and isolated by filtration, washing thoroughly with $\mathrm{MeOH}$. The isolated product was further purified by dissolving in a small amount of $\mathrm{CH}_{2} \mathrm{Cl}_{2}(5 \mathrm{~mL})$, precipitating into a vigorously stirring solution of pentanes $(300 \mathrm{~mL})$ and collected by filtration to yield a dark red solid $(0.58 \mathrm{~g}$, $0.81 \mathrm{mmol}, 87 \%$ yield).

${ }^{1} \mathrm{H} \mathrm{NMR} \mathrm{CDCl}_{3} . \delta 9.42(\mathrm{~s}, 2 \mathrm{H}), 7.02(\mathrm{~s}, 2 \mathrm{H}), 3.73(\mathrm{t}, 4 \mathrm{H}), 1.68$ $(\mathrm{m}, 4 \mathrm{H}), 1.36-1.28(\mathrm{~m}, 20 \mathrm{H}), 0.89(\mathrm{t}, 6 \mathrm{H})$.

${ }^{13} \mathrm{C} \mathrm{NMR} \mathrm{CDCl} 3 . \delta 167.2,144.0,132.6,131.3,127.7,126.7$, 121.5, 112.7, 40.4, 31.7, 29.2, 29.1, 27.3, 26.9, 22.6, 14.1. Expected: 16 peaks, experimental: 16 peaks.

MS (APCI-TOF). $\mathrm{m} / \mathrm{z}$ 713.1. Calcd 713.4.

Synthesis of $5,5^{\prime}$-dichloro-6, $6^{\prime}$-(dithiophen-2-yl)-1,1'-di(octyl) isoindigo (Oct-IICl $\mathbf{T h}_{2}$ ). A $10-20 \mathrm{~mL}$ glass vial was loaded bench top with 5,5'-dichloro-6,6'-dibromo-1,1'-di(octyl)isoindigo (0.54 g, $0.76 \mathrm{mmol}), 2$-tributylstannyl thiophene $(0.62 \mathrm{~g}$, $1.67 \mathrm{mmol})$, SiliaCat® DPP-Pd (0.15 g, $5 \mathrm{~mol} \%)$ and reagent grade toluene $(10 \mathrm{~mL})$. The dark red reaction mixture was sealed with a silicone cap and heated in a Biotage ${ }^{\circledR}$ Initiator+ 
microwave reactor for 5 minutes at $100{ }^{\circ} \mathrm{C}$ followed by 15 minutes at $170{ }^{\circ} \mathrm{C}$ under 5 bar of pressure. Following microwave irradiation, the dark purple-red reaction mixture was poured into $\mathrm{CH}_{2} \mathrm{Cl}_{2}(200 \mathrm{~mL})$ and set to stir with a $5: 1$ mixture of silica : $\mathrm{K}_{2} \mathrm{CO}_{3}$ to remove residual tin impurities. The solution was purified by filtering through silica-gel and the filtrate was concentrated under reduced pressure to yield a dark purple solid. The product was collected by filtration, washing with pentanes ( $0.48 \mathrm{~g}, 0.67 \mathrm{mmol}, 88 \%$ yield).

${ }^{1} \mathrm{H} \mathrm{NMR} \mathrm{CDCl}_{3} . \delta 9.43(\mathrm{~s}, 2 \mathrm{H}), 7.54\left(\mathrm{~d}, 2 \mathrm{H},{ }^{1} \mathrm{~J}_{\mathrm{H}-\mathrm{H}}=3 \mathrm{~Hz}\right), 7.47$ $\left(\mathrm{d}, 2 \mathrm{H},{ }^{1} J_{\mathrm{H}-\mathrm{H}}=3 \mathrm{~Hz}\right), 7.15\left(\mathrm{dd}, 2 \mathrm{H},{ }^{1} J_{\mathrm{H}-\mathrm{H}}=4 \mathrm{~Hz},{ }^{2} J_{\mathrm{H}-\mathrm{H}}=1 \mathrm{~Hz}\right)$, $6.92(\mathrm{~s}, 2 \mathrm{H}), 3.79(\mathrm{t}, 4 \mathrm{H}), 1.72(\mathrm{~m}, 4 \mathrm{H}), 1.37-1.28$ (m, 20H), 0.87 $(\mathrm{t}, 6 \mathrm{H})$.

${ }^{13}$ C NMR CDCl. $\delta$ 167.5, 143.6, 140.2, 136.3, 132.3, 132.1, 128.7, 127.4, 127.3, 125.2, 121.5, 109.5, 40.2, 31.8, 29.2, 29.2, 27.4, 27.0, 22.6, 14.1. Expected: 20 peaks, experimental: 20 peaks.

MS (APCI-TOF). $m / z$ 719.2. Calcd 719.8.

Synthesis of 5,5-dichloro-6,6'-bis(thiophen-5,2-diyl)bis(2-(1ethylpropyl)phthalimide)-1,1'-di(octyl)isoindigo (S3). A 2-5 mL glass vial was loaded bench top with 5,5'-dichloro-6,6'-di(thiophen-2-yl)-1,1'-di(octyl)isoindigo ( $0.25 \mathrm{~g}, 0.35 \mathrm{mmol}$ ), 4-bromo1-(ethylpropyl)phthalimide $(0.25 \mathrm{~g}, 0.84 \mathrm{mmol})$, potassium carbonate $(0.11 \mathrm{~g}, 0.80 \mathrm{mmol})$, SiliaCat ${ }^{\circledR}$ DPP-Pd $(0.09 \mathrm{~g}$, $5 \mathrm{~mol} \%)$, pivalic acid $(0.02 \mathrm{~g}, 0.2 \mathrm{mmol})$ and DMA ( $4 \mathrm{~mL})$. The purple reaction mixture was sealed with a silicone cap and stirred in an oil bath at $80{ }^{\circ} \mathrm{C}$ for 16 hours. The resultant black reaction mixture was dissolved in $\mathrm{CH}_{2} \mathrm{Cl}_{2}(100 \mathrm{~mL})$ and filtered through silica-gel to isolate from the heterogeneous catalyst with thorough washing with dichloromethane $(300 \mathrm{~mL})$. The filtrate was concentrated under reduced pressure and was liquid loaded on a SiliaSep ${ }^{\mathrm{TM}} 25 \mathrm{~g}$ cartridge and purified by flash column chromatography with dichloromethane as the eluent. The final product can be isolated by filtration from $\mathrm{MeOH}$, washing with hot iPrOH to yield a purple-black solid $(0.23 \mathrm{~g}$, $0.20 \mathrm{mmol}, 57 \%$ yield).

${ }^{1} \mathrm{H} \mathrm{NMR}\left(\mathrm{CDCl}_{3}\right) \cdot \delta 9.45(\mathrm{~s}, 2 \mathrm{H}), 8.04(\mathrm{~s}, 2 \mathrm{H}), 7.91\left(\mathrm{~d}, 2 \mathrm{H},{ }^{1} J_{\mathrm{H}-\mathrm{H}}\right.$ $=8 \mathrm{~Hz}), 7.57\left(\mathrm{~d}, 2 \mathrm{H},{ }^{1} J_{\mathrm{H}-\mathrm{H}}=4 \mathrm{~Hz}\right), 7.46\left(\mathrm{~d}, 2 \mathrm{H},{ }^{1} J_{\mathrm{H}-\mathrm{H}}=4 \mathrm{~Hz}\right)$, $6.92(\mathrm{~s}, 2 \mathrm{H}), 4.07(\mathrm{~m}, 2 \mathrm{H}) 3.85(\mathrm{t}, 4 \mathrm{H}), 2.09(\mathrm{~m}, 4 \mathrm{H}), 1.81(\mathrm{~m}, 8 \mathrm{H})$, 1.43-1.30 (m, 20H), $0.91(\mathrm{t}, 18 \mathrm{H})$.

${ }^{13} \mathrm{C} \mathrm{NMR}\left(\mathrm{CDCl}_{3}\right) . \delta 168.4,168.3,167.4,143.7,143.6,141.6$, $139.5,135.2,133.0,132.4,132.1,130.4,130.2,130.0,125.4$, 124.8, 123.8, 121.9, 119.8, 108.6, 55.8, 40.3, 31.8, 29.3, 29.2, 27.5, 27.0, 25.3, 22.6, 14.1, 11.2. Theoretical: 31 peaks, experimental: 31 peaks.

MS (APCI-TOF). $\mathrm{m} / \mathrm{z}$ 1149.4. Calcd 1150.3.

$E A$. Calculated for $\mathrm{C}_{66} \mathrm{H}_{70} \mathrm{Cl}_{2} \mathrm{~N}_{4} \mathrm{O}_{6} \mathrm{~S}_{2}$ : C, 68.9; H, 6.1; N, 4.9. Found: C, 69.0; H, 5.9; N, 4.9 .

Synthesis of 5,5-dichloro-6, $6^{\prime}$-bis(thiophen-5,2-diyl)bis(2-(1ethylpropyl)naphthalimide)-1,1'-di(octyl)isoindigo (S4). A 2-5 $\mathrm{mL}$ glass vial was loaded bench top with 5,5'-dichloro-6, $6^{\prime}$ di(thiophen-2-yl)-1,1'-di(octyl)isoindigo (0.20 g, $0.28 \mathrm{mmol}$ ), 4bromo-1-(ethylpropyl)naphthalimide $(0.26 \mathrm{~g}, 0.75 \mathrm{mmol})$, potassium carbonate $(0.11 \mathrm{~g}, 0.80 \mathrm{mmol})$, SiliaCat $\AA$ DPP-Pd (0.07 g, $5 \mathrm{~mol} \%)$, pivalic acid (0.02 g, $0.2 \mathrm{mmol})$ and DMA (4 mL). The purple reaction mixture was sealed with a silicone cap and stirred in an oil bath at $80{ }^{\circ} \mathrm{C}$ for 16 hours. The resultant black reaction mixture was dissolved in $\mathrm{CH}_{2} \mathrm{Cl}_{2}(100 \mathrm{~mL})$ and filtered through silica-gel to isolate from the heterogeneous catalyst with thorough washing with dichloromethane (300 $\mathrm{mL}$ ). The filtrate was concentrated under reduced pressure and was liquid loaded on a SiliaSep ${ }^{\mathrm{TM}} 25 \mathrm{~g}$ cartridge and purified by flash column chromatography with dichloromethane as the eluent. The final product can be isolated by filtration from $\mathrm{MeOH}$, washing with hot iPrOH to yield a purple-black solid (0.22 g, $0.18 \mathrm{mmol}, 64 \%$ yield).

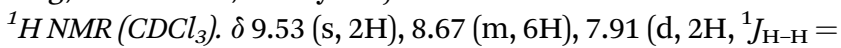
$8 \mathrm{~Hz}), 7.81(\mathrm{~m}, 2 \mathrm{H}), 7.71\left(\mathrm{~d}, 2 \mathrm{H},{ }^{1} J_{\mathrm{H}-\mathrm{H}}=4 \mathrm{~Hz}\right), 7.42\left(\mathrm{~d}, 2 \mathrm{H},{ }^{1} J_{\mathrm{H}-\mathrm{H}}=\right.$ $4 \mathrm{~Hz}), 7.05(\mathrm{~s}, 2 \mathrm{H}), 5.09(\mathrm{~m}, 2 \mathrm{H}) 3.87(\mathrm{~m}, 4 \mathrm{H}), 2.27(\mathrm{~m}, 4 \mathrm{H}), 1.95(\mathrm{~m}$, $4 \mathrm{H}), 1.79(\mathrm{~m}, 4 \mathrm{H}), 1.42-1.29(\mathrm{~m}, 20 \mathrm{H}), 0.94(\mathrm{t}, 12 \mathrm{H}), 0.87(\mathrm{t}, 6 \mathrm{H})$.

${ }^{13} \mathrm{C} \mathrm{NMR}\left(\mathrm{CDCl}_{3}\right) . \delta 167.5,143.8,142.2,141.8,138.0,135.6$, $132.4,131.8,130.7,129.7,129.4$, 129.1, 128.6, 127.4, 125.2, 121.9, 109.1, 99.0, 57.5, 40.3, 31.8, 29.3, 29.2, 27.5, 27.0, 25.0, 22.6, 14.0, 11.3. Theoretical: 35 peaks, experimental: 29 peaks. MS (APCI-TOF). $\mathrm{m} / \mathrm{z}$ 1249.4. Calcd 1250.4.

$E A$. Calculated for $\mathrm{C}_{74} \mathrm{H}_{74} \mathrm{Cl}_{2} \mathrm{~N}_{4} \mathrm{O}_{6} \mathrm{~S}_{2}: \mathrm{C}, 71.1 ; \mathrm{H}, 6.0 ; \mathrm{N}, 4.5$. Found: C, 70.9; H, 5.8; N, 4.5.

\subsection{Device fabrication}

BHJ OSC devices were fabricated using commercially available ITO-coated glass substrates (Lumtec), cleaned by sequentially ultrasonicating detergent and deionized water, acetone, and ethanol, and followed by exposure to UV/ozone. ZnO was deposited as a sol-gel precursor solution, following the method of Sun et al., ${ }^{77} 500 \mathrm{mg}$ of zinc acetate dihydrate were dissolved in $5 \mathrm{~mL}$ of 2-methoxyethanol with $142 \mu \mathrm{L}$ of ethanolamine and stirred overnight at room temperature in air. The room temperature solution was spin-cast unfiltered at a speed of 5000 $\mathrm{rpm}$, then annealed at $200{ }^{\circ} \mathrm{C}$ in air for 1 hour, for an expected thickness of $30 \mathrm{~nm}$. Active layers solutions of $\boldsymbol{p}$-DTS(FBTTh $\mathbf{F}_{2}$ and S1-4 were prepared with a total concentration of $20 \mathrm{mg}$ $\mathrm{mL}^{-1}$ in chlorobenzene with $0.4 \mathrm{v} / \mathrm{v} \%$ 1,8-diiodooctane (TCI Chemicals) additive. Solutions were heated to $80{ }^{\circ} \mathrm{C}$ and stirred overnight prior to hot-casting through a PTFE filter and spinning at a speed of $1000 \mathrm{rpm}$. Top contacts of $5.5 \mathrm{~nm}$ of molybdenum oxide followed by $110 \mathrm{~nm}$ of silver were thermally deposited under vacuum. The active areas of resulting devices were $0.04 \mathrm{~cm}^{2}$. Completed devices were then transferred directly into an Ar glovebox and tested using a xenon short arc lamp fully reflective solar simulator (Sciencetech SS-0.5k). Light from the simulator was passed through a neutral density filter to match AM 1.5G illumination with a power density of $100 \mathrm{~mW}$ $\mathrm{cm}^{-2}$ (calibrated with a standardized silicon photodetector immediately prior to use).

\section{Author contributions}

All authors have given approval to the final version of the manuscript.

\section{Funding sources}

GCW acknowledges NSERC Discovery Program, Canada Research Chairs, and the Canadian Foundation for Innovation. 
IGH acknowledges the NSERC Discovery Program, NSERC Photovoltaics Innovation Network and the Canadian Foundation for Innovation. JMT acknowledges NSERC CREATE DREAMS for financial support. JPS acknowledges Killam Trusts, NSERC and NSERC CREATE DREAMS for financial support.

\section{Acknowledgements}

We thank Abby Payne, Andrew Namespetra and Arthur Hendsbee for helpful discussions.

\section{References}

1 S. B. Darling and F. You, RSC Adv., 2013, 3(39), 17633.

2 S. R. Forrest, Nature, 2004, 428(6986), 911.

3 M. Kaltenbrunner, M. S. White, E. D. Głowacki, T. Sekitani, T. Someya, N. S. Sariciftci and S. Bauer, Nat. Commun., 2012, 3, 770.

4 B. Kippelen and J.-L. Brédas, Energy Environ. Sci., 2009, 2(3), 251.

5 G. Li, R. Zhu and Y. Yang, Nat. Photonics, 2012, 6(3), 153.

6 R. Søndergaard, M. Hösel, D. Angmo, T. T. Larsen-Olsen and F. C. Krebs, Mater. Today, 2012, 15(1-2), 36.

7 Y.-W. Su, S.-C. Lan and K.-H. Wei, Mater. Today, 2012, 15(12), 554.

8 G. Dennler, M. C. Scharber and C. J. Brabec, Adv. Mater, 2009, 21(13), 1323.

9 D. Gendron and M. Leclerc, Energy Environ. Sci., 2011, 4(4), 1225.

10 C. Duan, F. Huang and Y. Cao, J. Mater. Chem., 2012, 22(21), 10416.

11 J. Roncali, P. Leriche and P. Blanchard, Adv. Mater., 2014, 26(23), 3821.

12 J. Roncali, Acc. Chem. Res., 2009, 42(11), 1719.

13 G. C. Welch, R. C. Bakus, S. J. Teat and G. C. Bazan, J. Am. Chem. Soc., 2013, 135(6), 2298.

14 Z. B. Henson, G. C. Welch, T. van der Poll and G. C. Bazan, J. Am. Chem. Soc., 2012, 134(8), 3766.

15 C. J. Takacs, Y. Sun, G. C. Welch, L. A. Perez, X. Liu, W. Wen, G. C. Bazan and A. J. Heeger, J. Am. Chem. Soc., 2012, 134(40), 16597.

16 J. E. Coughlin, Z. B. Henson, G. C. Welch and G. C. Bazan, Acc. Chem. Res., 2014, 47(1), 257.

17 F. Zhang, D. Wu, Y. Xu and X. Feng, J. Mater. Chem., 2011, 21(44), 17590.

18 B. Walker, C. Kim and T.-Q. Nguyen, Chem. Mater., 2011, 23(3), 470.

19 Y. Lin, Y. Li and X. Zhan, Chem. Soc. Rev., 2012, 41(11), 4245.

20 Y. Chen, X. Wan and G. Long, Acc. Chem. Res., 2013, 46(11), 2645.

21 P. Sonar, J. P. F. Lim and K. L. Chan, Energy Environ. Sci., 2011, 4(5), 1558.

22 Y. Lin, Z.-G. Zhang, H. Bai, J. Wang, Y. Yao, Y. Li, D. Zhu and X. Zhan, Energy Environ. Sci., 2014, 8, 610.

23 X. Zhang, C. Zhan and J. Yao, Chem. Mater., 2014, 27, 166.

24 Y. Zhong, M. T. Trinh, R. Chen, W. Wang, P. P. Khlyabich, B. Kumar, Q. Xu, C.-Y. Nam, M. Y. Sfeir, C. Black,
M. L. Steigerwald, Y.-L. Loo, S. Xiao, F. Ng, X.-Y. Zhu and C. Nuckolls, J. Am. Chem. Soc., 2014, 136(43), 15215.

25 Y. Lin, J. Wang, Z.-G. Zhang, H. Bai, Y. Li, D. Zhu and X. Zhan, Adv. Mater., 2015, 27, 1170.

26 J. Zhao, Y. Li, H. Lin, Y. Liu, K. Jiang, C. Mu, T. Ma, J. Y. L. Lai, H. Hu, D. Yu and H. Yan, Energy Environ. Sci., 2015, 8, 520.

27 S. M. McAfee, J. M. Topple, I. G. Hill and G. C. Welch, J. Mater. Chem. A, 2015, 3, 16393.

28 A. F. Eftaiha, J.-P. Sun, I. G. Hill and G. C. Welch, J. Mater. Chem. A, 2013, 2(5), 1201.

29 Y. Lin and X. Zhan, Mater. Horiz., 2014, 1(5), 470.

30 E. Kozma and M. Catellani, Dyes Pigm., 2013, 98(1), 160.

31 J. E. Anthony, Chem. Mater., 2011, 23(3), 583.

32 C. L. Chochos, N. Tagmatarchis and V. G. Gregoriou, RSC Adv., 2013, 3(20), 7160.

33 P. Hudhomme, EPJ Photovoltaics, 2013, 4, 40401.

34 L. Schmidt-Mende, A. Fechtenkötter, K. Müllen, E. Moons,

R. H. Friend and J. D. MacKenzie, Science, 2001, 293(5532), 1119.

35 J. H. Schön, C. Kloc and B. Batlogg, Appl. Phys. Lett., 2000, $77(23), 3776$.

36 C. W. Struijk, A. B. Sieval, J. E. J. Dakhorst, M. van Dijk, P. Kimkes, R. B. M. Koehorst, H. Donker, T. J. Schaafsma, S. J. Picken, A. M. van de Craats, J. M. Warman, H. Zuilhof and E. J. R. Sudhölter, J. Am. Chem. Soc., 2000, 122(45), 11057.

37 J. Li, F. Dierschke, J. Wu, A. C. Grimsdale and K. Müllen, J. Mater. Chem., 2006, 16(1), 96.

38 Z. Chen, A. Lohr, C. R. Saha-Möller and F. Würthner, Chem. Soc. Rev., 2009, 38(2), 564.

39 T. Ye, R. Singh, H.-J. Butt, G. Floudas and P. E. Keivanidis, ACS Appl. Mater. Interfaces, 2013, 5(22), 11844.

40 A. Sharenko, D. Gehrig, F. Laquai and T.-Q. Nguyen, Chem. Mater., 2014, 26(14), 4109.

41 R. Singh, E. Aluicio-Sarduy, Z. Kan, T. Ye, R. C. I. MacKenzie and P. E. Keivanidis, J. Mater. Chem. A, 2014, 2(35), 14348.

42 Y. Lin, Y. Wang, J. Wang, J. Hou, Y. Li, D. Zhu and X. Zhan, Adv. Mater., 2014, 26(30), 5137.

43 Y. Liu, C. Mu, K. Jiang, J. Zhao, Y. Li, L. Zhang, Z. Li, J. Y. L. Lai, H. Hu, T. Ma, R. Hu, D. Yu, X. Huang, B. Z. Tang and H. Yan, Adv. Mater., 2014, 27, 1015.

44 P. E. Hartnett, A. Timalsina, H. S. S. R. Matte, N. Zhou, X. Guo, W. Zhao, A. Facchetti, R. P. H. Chang, M. C. Hersam, M. R. Wasielewski and T. J. Marks, J. Am. Chem. Soc., 2014, 136(46), 16345.

45 S. Holliday, R. S. Ashraf, C. B. Nielsen, M. Kirkus, J. A. Röhr, C.-H. Tan, E. Collado-Fregoso, A.-C. Knall, J. R. Durrant, J. Nelson and I. McCulloch, J. Am. Chem. Soc., 2014, 137(2), 898.

46 H. Li, T. Earmme, G. Ren, A. Saeki, S. Yoshikawa, N. M. Murari, S. Subramaniyan, M. J. Crane, S. Seki and S. A. Jenekhe, J. Am. Chem. Soc., 2014, 136(41), 14589.

47 J. T. Bloking, T. Giovenzana, A. T. Higgs, A. J. Ponec, E. T. Hoke, K. Vandewal, S. Ko, Z. Bao, A. Sellinger and M. D. McGehee, Adv. Energy Mater., 2014, 4(12), 1301426. 
48 H. Shi, W. Fu, M. Shi, J. Ling and H. Chen, J. Mater. Chem. A, 2015, 3, 1902.

49 Y. Kim, C. E. Song, S.-J. Moon and E. Lim, Chem. Commun., 2014, 50(60), 8235.

50 H. Bai, Y. Wang, P. Cheng, J. Wang, Y. Wu, J. Hou and X. Zhan, J. Mater. Chem. A, 2014, 3, 1910.

51 S. M. McAfee, J. M. Topple, A.-J. Payne, J.-P. Sun, I. G. Hill and G. C. Welch, ChemPhysChem, 2015, 16, 1190.

52 H.-C. Liao, C.-C. Ho, C.-Y. Chang, M.-H. Jao, S. B. Darling and W.-F. Su, Mater. Today, 2013, 16(9), 326.

53 C. V. Hoven, X.-D. Dang, R. C. Coffin, J. Peet, T.-Q. Nguyen and G. C. Bazan, Adv. Mater., 2010, 22(8), E63.

54 T.-H. Lai, S.-W. Tsang, J. R. Manders, S. Chen and F. So, Mater. Today, 2013, 16(11), 424.

55 H. Choi, H.-B. Kim, S.-J. Ko, J. Y. Kim and A. J. Heeger, Adv. Mater., 2015, 27(5), 892.

56 J. Jo, J.-R. Pouliot, D. Wynands, S. D. Collins, J. Y. Kim, T. L. Nguyen, H. Y. Woo, Y. Sun, M. Leclerc and A. J. Heeger, Adv. Mater., 2013, 25(34), 4783.

57 O. K. Kwon, J.-H. Park, D. W. Kim, S. K. Park and S. Y. Park, Adv. Mater., 2015, 27, 1951.

58 O. K. Kwon, J.-H. Park, S. K. Park and S. Y. Park, Adv. Energy Mater., 2015, 5(1), 1400929.

59 X. Zhang, J. Zhang, H. Lu, J. Wu, G. Li, C. Li, S. Li and Z. Bo, J. Mater. Chem. C, 2015, 3(27), 6979.

60 A. D. Hendsbee, J.-P. Sun, L. R. Rutledge, I. G. Hill and G. C. Welch, J. Mater. Chem. A, 2014, 2(12), 4198.

61 S. M. McAfee, J. S. J. McCahill, C. M. Macaulay, A. D. Hendsbee and G. C. Welch, RSC Adv., 2015, 5(33), 26097.

62 J. Areephong, A. D. Hendsbee and G. C. Welch, New J. Chem., 2015, 39(9), 6714.

63 A. D. Hendsbee, S. M. McAfee, J.-P. Sun, T. M. McCormick, I. G. Hill and G. C. Welch, J. Mater. Chem. C, 2015, 3(34), 8904.
64 Y. Deng, W. Li, L. Liu, H. Tian, Z. Xie, Y. Geng and F. Wang, Energy Environ. Sci., 2015, 8(2), 585.

65 Y. Yang, R. Wu, X. Wang, X. Xu, Z. Li, K. Li and Q. Peng, Chem. Commun., 2013, 50(4), 439.

66 T. Lei, J.-H. Dou, Z.-J. Ma, C.-H. Yao, C.-J. Liu, J.-Y. Wang and J. Pei, J. Am. Chem. Soc., 2012, 134(49), 20025.

67 T. Lei, J.-H. Dou, Z.-J. Ma, C.-J. Liu, J.-Y. Wang and J. Pei, Chem. Sci., 2013, 4(6), 2447.

68 T. M. Pappenfus, K. B. Schliep, A. Dissanayake, T. Ludden, B. Nieto-Ortega, J. T. López Navarrete, M. C. Ruiz Delgado and J. J. Casado, Chem. Educ., 2012, 89(11), 1461.

69 P. Sonar, E. L. Williams, S. P. Singh, S. Manzhos and A. Dodabalapur, Phys. Chem. Chem. Phys., 2013, 15(40), 17064.

70 S. H. Yoo, J. M. Kum and S. O. Cho, Nanoscale Res. Lett., 2011, 6(1), 545.

71 T. M. McCormick, C. R. Bridges, E. I. Carrera, P. M. DiCarmine, G. L. Gibson, J. Hollinger, L. M. Kozycz and D. S. Seferos, Macromolecules, 2013, 46(10), 3879.

72 Y.-A. Duan, Y. Geng, H.-B. Li, J.-L. Jin, Y. Wu and Z.-M. Su, J. Comput. Chem., 2013, 34(19), 1611.

73 L. Pandey, C. Risko, J. E. Norton and J.-L. Brédas, Macromolecules, 2012, 45(16), 6405.

74 L. R. Rutledge, S. M. McAfee and G. C. Welch, J. Phys. Chem. A, 2014, 118, 7939.

75 J. M. Topple, S. M. McAfee, G. C. Welch and I. G. Hill, Org. Electron., DOI: 10.1016/j.orgel.2015.09.020.

76 W. Jiang, J. Tang, Q. Qi, W. Wu, Y. Sun and D. Fu, Dyes Pigm., 2009, 80(1), 11.

77 Y. Sun, J. H. Seo, C. J. Takacs, J. Seifter and A. J. Heeger, Adv. Mater., 2011, 23(14), 1679. 